\title{
Avascular necrosis of the femoral head due to low-dose corticosteroid used in a patient with panhypopituitarism: A case report and literature review
}

\author{
Murat Çalapkulu, MD®D, Muhammed Kızılgül, MD(D), Muhammed Erkam Sencar, MD®D,

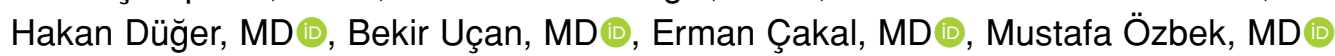 \\ Department of Endocrinology and Metabolism, University of Health Sciences Dışkapı Yıldırım Beyazıt Training and \\ Research Hospital, Ankara, Turkey
}

Glucocorticoids are drugs that exhibit immunosuppressive and antiinflammatory effects at appropriate therapeutic doses. Many side effects are encountered during glucocorticoid treatment. Osteoporosis is a common side effect on bone metabolism, while avascular necrosis (AVN) is a rare side effect. ${ }^{[1]}$ The causes of AVN include interruption of the vascular supply as a result of local trauma or non-traumatic systemic conditions. Non-traumatic systemic conditions associated with AVN include corticosteroid administration, fat emboli, hemoglobinopathies (e.g., sickle cell anemia), systemic lupus erythematosus, and alcoholism. ${ }^{[2]}$ Avascular necrosis is also known as aseptic necrosis or osteonecrosis, which occurs in approximately $3-40 \%$ of patients receiving corticosteroids. The most common site of involvement is the femoral head, which may lead to severe morbidity. ${ }^{[2]}$ The risk of glucocorticoid-induced osteonecrosis is associated with the dose and the duration of glucocorticoid use. ${ }^{[3,4]}$ In most cases, AVN is a result of high doses of steroids given for a long period of time, and

Received: December 09, 2019

Accepted: February 05, 2020

Published online: June 18, 2020

Correspondence: Murat Çalapkulu, MD. Dıșkapı Yıldırım Beyazı† Eğitim ve Araştırma Hastanesi, Endokrinoloji ve Metabolizma Kliniği, 06110 Dışkapı, Ankara, Türkiye.

E-mail: calapkulumurat89@gmail.com

Doi: $10.5606 /$ ehc. 2020.72773

Citation: Çalapkulu M, Kızılgül M, Sencar ME, Düğer H, Uçan B, Çakal E, et al. Avascular necrosis of the femoral head due to lowdose corticosteroid used in a patient with panhypopituitarism: A casereportand literature review. JtDisRelatSurg 2020;31(2):390-394.

\section{ABSTRACT}

Osteonecrosis, commonly known as avascular necrosis (AVN) of bone, is one of the universally recognized side effects of high-dose steroids and commonly involves femur head leading to significant morbidity. However, the development of AVN in the femoral head due to low-dose oral corticosteroid therapy in a short time is a rare occurrence. Management by stopping corticosteroid treatment can be challenging in many cases due to the adrenal crisis. Glucocorticoids may have to be continued in the lowest possible dose using a physiological preparation, such as hydrocortisone, when the stoppage is not possible. In this article, we report a 34-year-old male patient with hypopituitarism who developed bilateral AVN while receiving a mild physiological replacement oral prednisolone dose for only three years for secondary adrenal insufficiency of hypopituitarism after transsphenoidal surgery. The patient was switched to hydrocortisone and underwent core decompressive surgery resulting in a reduction of hip pain and improvement. The case report intends to highlight the occurrence of AVN of the femur even with a very low dose of corticosteroid used for the treatment of panhypopituitarism. Avascular necrosis should be considered in the differential diagnosis in patients with hip pain, even in low-dose steroid use because early diagnosis is essential to prevent progression, collapse, and eventually the need for hip replacement in AVN.

Keywords: Avascular necrosis, corticosteroid, hypopituitarism, steroid side effects.

usually, such doses are used for immunosuppressive, chemotherapeutic, or anti-inflammatory effects. Since the usual doses used in endocrinology are physiological doses given as replacement for steroid deficiency, this complication is rarely seen in endocrinology practice.

A few cases of osteonecrosis due to the physiologic dose of glucocorticoids have been reported in the literature. ${ }^{[5-8]}$ However, some of these patients had a history of steroid use prior to pituitary surgery or 


\begin{tabular}{|lcc|}
\hline \multicolumn{3}{|c|}{ TABLE I } \\
\hline & Values & Reference range \\
\hline Free T4 $(\mathrm{ng} / \mathrm{dL})$ & 0.43 & $0.58-1.16$ \\
Free T3 $(\mathrm{ng} / \mathrm{dL})$ & 3 & $2.66-4.37$ \\
Thyroid stimulating hormone $(\mathrm{mlU} / \mathrm{L})$ & 4.1 & $0.38-5.33$ \\
Prolactin $(\mathrm{ng} / \mathrm{mL})$ & 3.71 & $2.64-13.13$ \\
Follicle stimulating hormone $(\mathrm{IU} / \mathrm{L})$ & 0.86 & $1.27-19.26$ \\
Luteinizing hormone $(\mathrm{IU} / \mathrm{L})$ & 0.11 & $1.24-8.62$ \\
Total testosterone $(\mathrm{ng} / \mathrm{dL})$ & 35 & $175-781$ \\
Growth hormone $(\mathrm{ng} / \mathrm{ml})$ & $<0.05$ & $0-3$ \\
Somatomedin C $(\mathrm{ng} / \mathrm{mL})$ & 40.8 & $63.4-223$ \\
Adrenocorticotropic hormone $(\mathrm{pg} / \mathrm{mL})$ & 5.28 & $0-46$ \\
Cortizol $(\mu \mathrm{g} / \mathrm{dL})$ & 0.1 & $6.7-22.6$ \\
\hline
\end{tabular}

for some other reason, and some had used steroids for more than 10 years. Therefore, it is difficult to speculate in these cases whether previous exposure to steroid treatment or a long steroid treatment period contributed to AVN. In present case, there was no history of steroid use preoperatively, and bilateral AVN developed in less than three years. In this article, we aimed to present the development of low-dose prednisolone treatment-related AVN in a patient with secondary adrenal insufficiency due to surgery for non-functional pituitary adenoma.

\section{CASE REPORT}

Our case is a 34-year-old male patient who was operated for a non-secreting pituitary macroadenoma

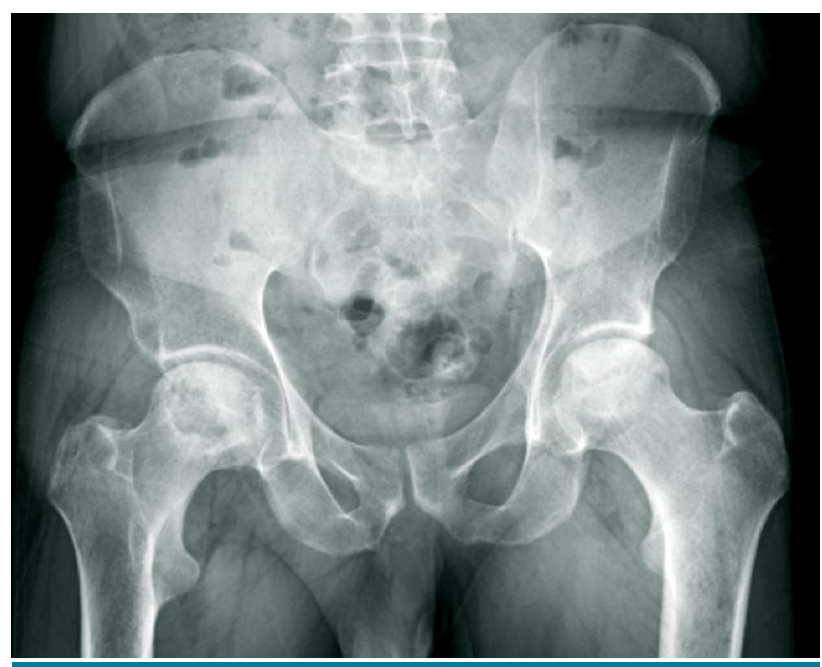

FIGURE 1. Anteroposterior view of pelvis showing flattening of outer portion of bilateral femoral head from avascular necrosis, with adjacent joint space narrowing. four years ago and who eventually developed secondary adrenal and thyroid insufficiency. He did not attend regular follow-up for the last three years, either in the surgery or endocrinology unit. He started having pain in bilateral hip associated with limping approximately three years after initiation of prednisolone therapy (daily dose $5 \mathrm{mg}$ ). He was admitted to our clinic with hip pain, weakness, fatigue, and nausea ongoing for the last three months. The patient started to use crutches and had difficulty in walking. He was diagnosed with osteonecrosis of femoral head three months ago, and he stopped prednisolone and thyroxine treatment by himself. He did not consume alcohol or cigarettes. Biochemical investigations were consistent with panhypopituitarism (Table I). X-ray and hip magnetic resonance imaging (MRI) showed AVN at the femoral head (Figures 1 and 2). Adenoma or residual mass was not detected in pituitary MRI. Hydrocortisone (10 mg/day) was started for secondary adrenal insufficiency as it was believed to be the more physiological preparation compared to other glucocorticoids. Levothyroxine was initiated one week later for secondary hypothyroidism, initially at $100 \mu \mathrm{g} / \mathrm{day}$, and later increased to $125 \mu \mathrm{g} /$ day. Injectable testosterone was also initiated at a dose of $250 \mathrm{mg} / \mathrm{monthly}$ as intramuscular injection. The patient underwent core decompression surgery for left hip and given vitamin D and calcium supplementation. Hip replacement therapy was planned for the right hip. Significant improvement was achieved in the patient's symptoms and findings after the treatment. Also, his hip pain subsided, and he started to walk without crutches three months after surgery. In the sixth month follow-up, he was still on low-dose glucocorticoid replacement, which 

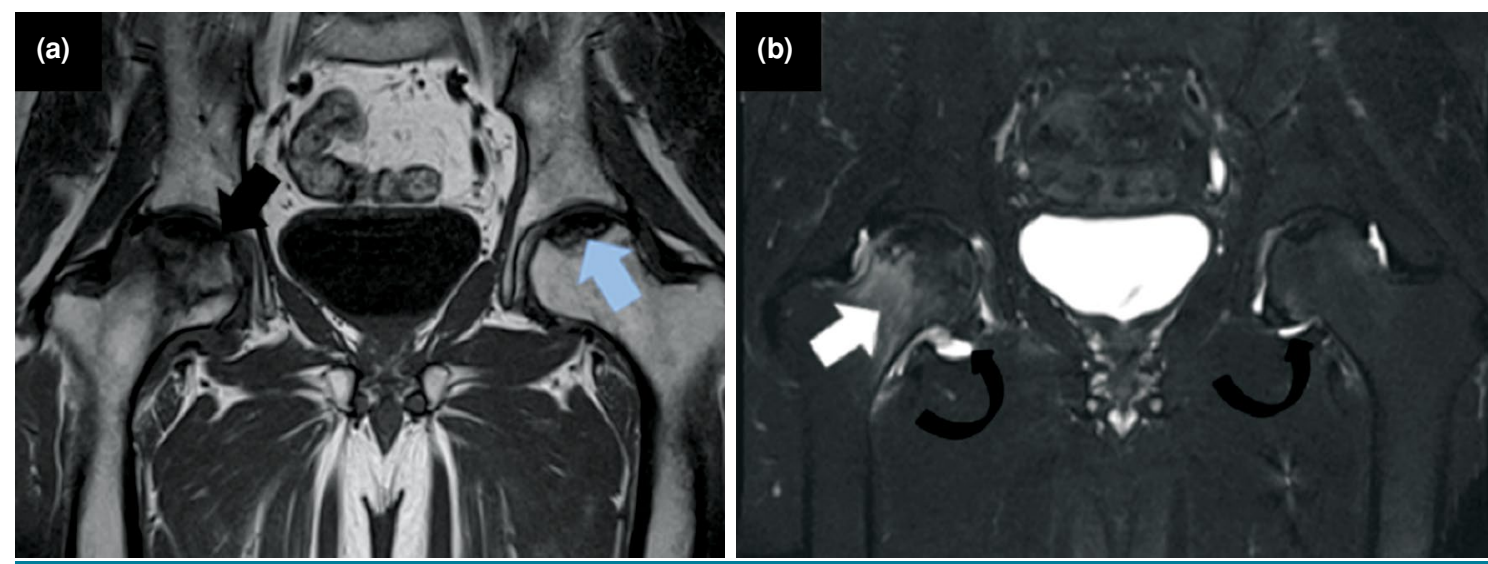

FIGURE 2. (a) T1 coronal and (b) short tau inversion recovery coronal magnetic resonance imaging of hip demonstrating bilateral hip avascular necrosis more advanced on right side which displays focal depression of femoral head and irregular femoral epiphysis (a, black arrow) with marrow edema extending to neck (b, white arrow). On left side, there is crescent sign of femoral head ( $a$, blue arrow). Bilateral hip joint effusion is seen more on right side (b, curved arrows).

would continue lifelong. Unfortunately, the patient could not come to the follow-up examinations because he moved to another city after six months of follow-up. Therefore, we could not know whether the replacement therapy was performed for the right hip. A written informed consent was obtained from the patient.

\section{DISCUSSION}

Avascular necrosis is a disease associated with high morbidity and disability. Early diagnosis has the potential to reduce morbidity and to improve the patient's quality of life. However, despite the technological improvements in diagnosis, detection remains difficult due to the lack of early clinical symptoms. As with many other insidious diseases, suspecting AVN can help uncover those patients who may be suffering from the disease but who do not have severe clinical symptoms. Although most cases of AVN result from trauma, non-traumatic AVN should be suspected in patients with a predilection for the disease. Avascular necrosis is one of the important complications of glucocorticoid therapy occurring in up to $40 \%$ of patients, and high-dose use of corticosteroids is the most common cause of non-traumatic AVN. ${ }^{[9]}$ Although the exact reason is unknown, a complex interplay and imbalance of bone resorption and formation, impairment of vasculature

\begin{tabular}{|c|c|c|c|c|c|c|}
\hline \multicolumn{7}{|c|}{$\begin{array}{l}\text { TABLE II } \\
\text { Reports of avascular necrosis with low-dose steroid treatment }\end{array}$} \\
\hline No & Author & Age/Gender & Steroid treatment & Treatment duration & Result & AVN treatment \\
\hline 1 & Spencer et al., ${ }^{[7]}$ & $27 / F$ & $\begin{array}{c}4 \mathrm{mg} \text { prednisolone } \\
\text { for renal } \\
\text { transplantation }\end{array}$ & 10 years & $\begin{array}{l}\text { Unilateral AVN } \\
\text { (right hip) }\end{array}$ & * \\
\hline 2 & Dharmshaktu et al., ${ }^{[5]}$ & $38 / \mathrm{M}$ & $\begin{array}{l}5 \text { mg prednisolone } \\
\text { for hypopituitarism }\end{array}$ & 2 years & Bilateral AVN & $\begin{array}{l}\text { Surgery, zoledronic } \\
\text { acid, calcium, } \\
\text { vitamin D }\end{array}$ \\
\hline 3 & Hossain et al., ${ }^{[8]}$ & $41 / F$ & $\begin{array}{l}25 \text { mg hydrocortisone } \\
\text { for hypopituitarism }\end{array}$ & 7 months & $\begin{array}{l}\text { Unilateral AVN } \\
\text { (right hip) }\end{array}$ & $\begin{array}{l}\text { Alendronate, } \\
\text { calcium, vitamin D }\end{array}$ \\
\hline 4 & Rajput et al., ${ }^{[6]}$ & $60 / F$ & $\begin{array}{l}5 \text { mg prednisolone } \\
\text { for Sheehan's } \\
\text { syndrome }^{\star \star}\end{array}$ & 16 years & Bilateral AVN & Not reported \\
\hline 5 & Present case & $34 / \mathrm{M}$ & $\begin{array}{l}5 \text { mg prednisolone } \\
\text { for hypopituitarism }\end{array}$ & 3 years & Bilateral AVN & $\begin{array}{l}\text { Surgery, calcium, } \\
\text { vitamin D }\end{array}$ \\
\hline
\end{tabular}


within the bone, and apoptosis could be possible mechanisms. ${ }^{[2,10]}$ In a study of 66 steroid-induced AVN cases, the most common associated route involved was intravenous steroids followed by oral and rarely intramuscular, intraarticular injections, and inhaled steroids. ${ }^{[1]}$ There is no exact cumulative dose for the development of AVN due to steroid use. Dimant et al. ${ }^{[12]}$ failed to find any correlation between peak dose, duration, or cumulative dose of steroid and the development of osteonecrosis. However, it appears that in the majority of the studies, patients who were at increased risk of AVN received a dose of greater than $10 \mathrm{mg} /$ day of prednisone, which is much higher than the dose of our patient. ${ }^{[13,14]}$ A meta-analysis suggested a 4.6-fold increase in the incidence of AVN with every $10 \mathrm{mg} /$ day increase in prednisone therapy. ${ }^{[14]} \mathrm{A}$ few cases of steroid-induced AVN where lower doses had been used have been reported (Table II). ${ }^{[5-8]}$ Rajput and Kulshreshtha ${ }^{[6]}$ reported bilateral AVN of the femoral head in a patient who received prednisolone for 16 years and hydrocortisone for one-and-half years for Sheehan syndrome. Spencer et al. ${ }^{[7]}$ reported AVN of the femoral head occurring after 10 years of oral prednisone dose of $4 \mathrm{mg} /$ day. However, the patient had also received intravenous methylprednisolone injection previously. Hossaina et al. ${ }^{[8]}$ reported unilateral AVN of the femoral head occurring after seven months of oral hydrocortisone dose of $25 \mathrm{mg} /$ day. However, the patient had menopause, which could be a contributing factor for steroid-induced osteonecrosis. Dharmshaktu et al. ${ }^{[5]}$ reported bilateral AVN with $5 \mathrm{mg} /$ day dose of oral prednisolone therapy over a duration of two years. However, the patient had a history of dexamethasone therapy at a dose of $2 \mathrm{mg} /$ day before prednisolone therapy. Similarly, we report bilateral AVN of the femoral head occurring after three years of oral prednisone at $5 \mathrm{mg} /$ day. Our patient had no history of using steroid therapy before and AVN developed in less than three years with low-dose prednisolone treatment.

Bisphosphonate, calcium, and vitamin D treatment were given to the reported cases. Dharmshaktu et al. ${ }^{[5]}$ reported that the patient underwent core decompression surgery with medical treatment. However, Hossaina et al. ${ }^{[8]}$ reported that the patient underwent hip replacement surgery with medical treatment. Steroid treatment was changed to hydrocortisone in both cases. In the present case, the patient was given calcium and vitamin $\mathrm{D}$ supplementation. Similarly to the literature, oral prednisone was switched to hydrocortisone. The bone mineral density result of the patient was compatible with osteopenia. Thus we could not administer bisphosphonate treatment to the patient because of the national healthcare system reimbursement conditions for bisphosphonate in Turkey. In addition, the patient also had esophagitis symptoms and did not wish to take bisphosphonate treatment. Core decompression surgery was performed on the left hip of the patient. Hip replacement therapy was planned for the right hip; however, the patient did not show up after six months of follow-up.

Osteonecrosis with such low doses of corticosteroids is a rare finding. Tokuhara et al. ${ }^{[15]}$ examined the relationship between osteonecrosis and steroid dose in white rabbits, and they observed that low levels of steroid metabolizing hepatic activity might increase the responsiveness to steroids and the risk of steroid-induced osteonecrosis even with low steroid dose.

In conclusion, when hip pain develops in patients receiving steroid therapy, AVN should be considered in the differential diagnosis. Early diagnosis of hip AVN is critical, as all treatments oriented to the preservation of the femoral head are more successful when applied in the early course of the disease. Management by stopping steroid treatment can be challenging in many cases due to the possibility of adrenal crisis. In such cases, standard management is reducing steroid to the lowest possible dose. This report intends to highlight the occurrence of AVN of the femur even with a very low dose of glucocorticoid used for the treatment of panhypopituitarism.

\section{Declaration of conflicting interests}

The authors declared no conflicts of interest with respect to the authorship and/or publication of this article.

\section{Funding}

The authors received no financial support for the research and/or authorship of this article.

\section{REFERENCES}

1. Canalis E, Mazziotti G, Giustina A, Bilezikian JP. Glucocorticoid-induced osteoporosis: pathophysiology and therapy. Osteoporos Int 2007;18:1319-28.

2. Assouline-Dayan Y, Chang C, Greenspan A, Shoenfeld $Y$, Gershwin ME. Pathogenesis and natural history of osteonecrosis. Semin Arthritis Rheum 2002;32:94-124.

3. Haberal B, Şahin O, Şimşek EK, Mahmuti A, Tuncay İC. Outcomes for core decompression with multiple drilling of the osteonecrosis of the femoral head in patients with solid organ transplantation. Eklem Hastalik Cerrahisi 2018;29:159-64.

4. Ficat RP, Arlet J. Cortisone associated necrosis of bone. In: Hungerford D, editor. Ischemia and necrosis of bone. Baltimore: Williams and Wilkins; 1980. p. 136-40. 
5. Dharmshaktu P, Aggarwal A, Dutta D, Kulshreshtha B. Bilateral femoral head avascular necrosis with a very low dose of oral corticosteroid used for panhypopituitarism. BMJ Case Rep 2016;2016:bcr2015212803.

6. Rajput S, Kulshreshtha B. Bilateral Femoral Head Avascular Necrosis with Physiological Doses of Steroids. Indian J Endocrinol Metab 2018;22:710-1.

7. Spencer JD, Humphreys S, Tighe JR, Cumming RR. Early avascular necrosis of the femoral head. Report of a case and review of the literature. J Bone Joint Surg [Br] 1986;68:414-7.

8. Hossaina MJ, Karandisha S, Khanala R, Parajulib PR, Mojahedia A. Unilateral Femoral Head Osteonecrosis Caused by Low-Dose Oral Corticosteroid Used for Secondary Adrenal Insufficiency From Idiopathic Hypopituitarism. J Med Cases 2017;8:227-9.

9. Bialas MC, Routledge PA. Adverse effects of corticosteroids. Adverse Drug React Toxicol Rev 1998;17:227-35.

10. Weinstein RS. Glucocorticoid-induced osteonecrosis. Endocrine 2012;41:183-90.
11. Powell C, Chang C, Naguwa SM, Cheema G, Gershwin ME. Steroid induced osteonecrosis: An analysis of steroid dosing risk. Autoimmun Rev 2010;9:721-43.

12. Dimant J, Ginzler EM, Diamond HS, Schlesinger M, Marino CT, Weiner M, Kaplan D. Computer analysis of factors influencing the appearance of aseptic necrosis in patients with SLE. J Rheumatol 1978;5:136-41.

13. Zizic TM, Marcoux C, Hungerford DS, Dansereau JV, Stevens MB. Corticosteroid therapy associated with ischemic necrosis of bone in systemic lupus erythematosus. Am J Med 1985;79:596-604.

14. Felson DT, Anderson JJ. Across-study evaluation of association between steroid dose and bolus steroids and avascular necrosis of bone. Lancet 1987;1:902-6.

15. Tokuhara Y, Wakitani S, Oda Y, Kaneshiro Y, Masada T, $\mathrm{Kim} \mathrm{M}$, et al. Low levels of steroid-metabolizing hepatic enzyme (cytochrome P450 3A) activity may elevate responsiveness to steroids and may increase risk of steroidinduced osteonecrosis even with low glucocorticoid dose. J Orthop Sci 2009;14:794-800. 